Article

\title{
Prediction of Mechanical Performance of Acetylated MDF at Different Humid Conditions
}

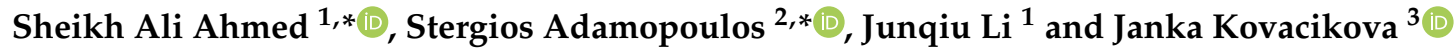 \\ 1 Department of Forestry and Wood Technology, Faculty of Technology, Linnaeus University, \\ Georg Lückligs Plats 1, 35195 Växjö, Sweden; j1223hc@student.lnu.se \\ 2 Department of Forest Biomaterials and Technology, Division of Wood Science and Technology, \\ Vallvägen 9C-D, 75651 Uppsala, Sweden \\ 3 Department of Mechanical Engineering, Faculty of Technology, Linnaeus University, Georg Lückligs Plats 1, \\ 35195 Växjö, Sweden; janka.kovacikova@lnu.se \\ * Correspondence: sheikh.ahmed@lnu.se (S.A.A.); stergios.adamopoulos@slu.se (S.A.); \\ Tel.: +46-470-76-7492 (S.A.A.); +46-018-67-2474 (S.A.)
}

Received: 19 November 2020; Accepted: 2 December 2020; Published: 4 December 2020

check for updates

\begin{abstract}
Change of relative humidity $(\mathrm{RH})$ in surrounding environment can greatly affect the physical and mechanical properties of wood-based panels. Commercially produced acetylated medium density fiberboard (MDF), Medite Tricoya ${ }^{\circledR}$, was used in this study to predict strength and stiffness under varying humid conditions by separating samples in parallel $(/ /)$ and perpendicular $(\perp)$ to the sanding directions. Thickness swelling, static moduli of elasticity $\left(\mathrm{MOE}_{\text {stat }}\right)$ and rupture $\left(\mathrm{MOR}_{\text {stat }}\right)$, and internal bond (IB) strength were measured at three different humid conditions, i.e., dry $(35 \% \mathrm{RH})$, standard (65\% RH) and wet (85\% RH). Internal bond (IB) strength was also measured after accelerated aging test. A resonance method was used to determine dynamic modulus of elasticity $\left(\mathrm{MOE}_{\mathrm{dyn}}\right)$ at the aforementioned humid conditions. Linear regression and finite element (FE) analyses were used to predict the MDF's static bending behavior. Results showed that dimensional stability, $\mathrm{MOE}_{\text {stat }}, \mathrm{MOR}_{\text {stat }}$ and IB strength decreased significantly with an increase in RH. No reduction of IB strength was observed after $426 \mathrm{~h}$ of accelerated aging test. A multiple regression model was established using $\mathrm{MOE}_{\text {dyn }}$ and $\mathrm{RH}$ values to predict $\mathrm{MOE}_{\text {stat }}$ and $\mathrm{MOR}_{\text {stat }}$. In both directions $(/ /$ and $\perp$ ), highly significant relationships were observed. The predicted and the measured values of $\mathrm{MOE}_{\text {stat }}$ and $\mathrm{MOR}_{\text {stat }}$ were satisfactorily related to each other, which indicated that the developed model can be effectively used for evaluating the strength and stiffness of Medite Tricoya ${ }^{\circledR}$ MDF samples at any humid condition. Percent errors of two different simulation techniques (standard and extended FE method) showed highly efficient way of simulating the MDF structures with low fidelity.
\end{abstract}

Keywords: acetylation; wood fiber; strength; stiffness; internal bonding strength; thickness swelling; regression; finite element analysis

\section{Introduction}

Medium density fiberboard (MDF) is manufactured with wood fibers bonded with water resistant adhesives such as phenol formaldehyde, urea formaldehyde, isocyanate resin, etc. [1,2]. MDF is primarily used in furniture, as a building material and for laminate flooring, since it has good strength and stiffness and it is easy to process. Compared to plywood, MDF panels generally swell more and may not be recovered after drying due to the inherent hygroscopicity of the wood fibers, the residual stresses formed in the fiber mat during hot pressing and some loss of the glue bonds [3]. As a result, when the MDF panel is exposed to any form of water, its constituent wood fibers swell and some of that residual stress is released, resulting in an increase of thickness of the panel. Thickness swelling 
markedly weakens the product [4], and the mechanical properties that are most directly affected are shear strength and moduli of elasticity and rupture [5]. Exposure to outdoor environment with varying climate conditions can result in dimensional changes and strength loss, and thus MDF panels are generally not recommended for exterior applications. In terms of computational modelling, these phenomena are considered to be the rheological behavior of the material [6].

Several studies have been carried out using various adhesive systems [7-9], post treatments [10], heat treated fibers [11], alternative fibers [12] and recycled adhesives [13] to improve strength and water resistance of MDF panels. In addition, chemical modification was also used to improve the material properties, such as moisture-related properties, durability and weathering resistance [14-16]. The most described chemical modification method for improved dimensional stability of wood particles and fibers to produce panel products is acetylation with acetic anhydride $[17,18]$. In acetylation process, acetic anhydride substitutes the hydroxyl $(-\mathrm{OH})$ groups in the wood cells with acetyl groups, resulting in decreased hygroscopicity and increased dimensional stability; while reductions in some mechanical properties also occur depending on the extent of temperature and time of the modification reaction [18-20]. Several explanations of the strength loss were given, as for example the type of the adhesive [21], bondability [22], press pressure [23], etc. Higher bondability is required if the panels are used under severe conditions for a long time. Thus, the effect of weathering on the dimensional changes and mechanical properties of acetylated MDF would be beneficial for predicting its long-term service behavior. Mechanical strength and stiffness along and perpendicular to the sanding direction should be also available to achieve better and proper assembly of acetylated MDF panels in outdoor applications.

Fiberboards can be exposed to a range of environmental conditions during service life. Moisture content of MDF, similar to other lignocellulosic materials, changes with the change of surrounding humidity and temperature. Therefore, it is important to know the relationship between moisture content and strength properties of MDF if used as a structural member subjected to these environmental conditions. Use of non-destructive acoustic testing could provide a rapid and reliable measurement of strength properties of MDF panels. Usually, acoustic testing is carried out by using time-of-flight (TOF) and resonance methods [24]. TOF methods use propagation time of a pulse of ultrasound or a stress wave across the material. On the other hand, resonance methods use the free vibration frequency of the material under forced harmonic vibration. Resonance methods provide more information on the elastic properties of materials and are thus considered more reliable than the TOF methods [25]. Previous studies showed a very good to strong relation between dynamic bending properties measured by acoustic tools with the static bending properties of wood panels $[26,27]$. However, values of dynamic bending properties vary depending on the method used and, most importantly, on the moisture content levels of wood panels. Prediction of static bending properties of acetylated MDF using acoustic techniques under different humid conditions is lacking. Considering that acetylated MDF is more hydrophobic than conventional MDF, fewer internal bond failures and associated changes of internal structure should be expected by repeated swelling and shrinkage. That in turn should lead to more stable static bending behavior. Nevertheless, establishing the relationship between acoustic and static bending properties of acetylated MDF at different humid conditions would ensure reliable and safe predictions of their performance for intended end uses.

Another available method to predict and analyze material behavior of MDF is creating macro scale finite element (FE) models of MDF board's structure. Following classic design procedures for macroscale modelling, the material characteristics obtained from the experiments presented in this paper were used as input values to define the material, and the geometry and boundary conditions of the experiment set up were imitated in the FE model. Here, two analysis approaches that are implemented in a SIMULIA ${ }^{\mathrm{TM}}$ Abaqus/CEA (Systèmes ${ }^{\circledR}$ ) were used to imitate a static three-point bending test. The first approach was a standard quasi-static stress/displacement procedure to control the time incrementation, and the approach is named T1 in this work [28]. Additionally, a second and more advanced technique, the extended finite element method (XFEM) [29], was used and is named T2. This technique allows us to model discontinuities as an enriched feature and it is an extension to 
the conventional finite element method [28]. Both techniques are classified as macroscale techniques that are nowadays typically used while designing structures [30,31]. The outcome of both analyses are displacements, reaction forces and maximum principal stresses of the studied FE models. These models should be later optimized to achieve higher fidelity, meaning to create more sophisticated models accounting for the environmental loads as well as mechanical loads, for example, multiscale models [32].

Yet, there is not enough systematic information on the dimensional stability and mechanical properties of acetylated MDF panels under different humid conditions. Establishing correlations between elastic properties measured nondestructively with bending strength and stiffness of acetylated MDF would lead to a quick and reliable means of assessment of the safety margins for different applications. Thus, this study was focused on elucidating the dimensional and static bending properties of acetylated MDF and on evaluating possibilities to predict its bending behavior from acoustic data by using standard statistical and multiscale prediction modelling methods. Dry (35\% RH), standard (65\% $\mathrm{RH})$ and wet $(85 \% \mathrm{RH})$ climatic conditions were considered to represent different moisture content situations as well as accelerated weathering.

\section{Materials and Methods}

\subsection{MDF Panels}

Commercially produced Medite Tricoya ${ }^{\circledR}$ MDF panels with dimensions of $300 \times 210 \times 18 \mathrm{~mm}^{3}$ (length $\times$ width $\times$ thickness) were used in this study. Formaldehyde free glue is used for the acetylated softwood fibres during the production of Tricoya ${ }^{\circledR}$ panels. Two different sample sets were prepared, i.e., along (parallel samples symbolized by //) and across (perpendicular samples symbolized by $\perp$ ) the sanding direction. Working samples were prepared according to Table 1 and were stored in three different climatic conditions, i.e., dry $\left(20^{\circ} \mathrm{C}, 35 \% \mathrm{RH}\right)$, standard $\left(20^{\circ} \mathrm{C}, 65 \% \mathrm{RH}\right)$ and wet $\left(20^{\circ} \mathrm{C}, 85 \%\right.$ $\mathrm{RH}$ ). Five replicates of MDF samples (two different directions and three climatic conditions depending on measured properties) were produced in a total of 80 samples, which were tested for different properties according to EN standards (Table 1).

Table 1. Dimensions (length $\times$ width $\times$ thickness) of samples used for measuring different physical and mechanical properties of Medite Tricoya ${ }^{\circledR}$ medium density fiberboard (MDF) samples.

\begin{tabular}{ccccc}
\hline Type & Properties Measured & $\begin{array}{c}\text { Dimensions } \\
{\left[\mathbf{m m}^{3}\right]}\end{array}$ & $\begin{array}{c}\text { Sample } \\
\text { Number }\end{array}$ & $\begin{array}{c}\text { Standard } \\
\text { Followed }\end{array}$ \\
\hline \multirow{4}{*}{ Physical properties } & Moisture content & $50 \times 50 \times 18$ & 15 & EN 322 [33] \\
& Density & $50 \times 50 \times 18$ & 15 & EN 323 [34] \\
& Dimensional changes & $300 \times 50 \times 18$ & 10 & EN 318 [35] \\
& Thickness swelling & $50 \times 50 \times 18$ & 5 & EN 317 [36] \\
& Accelerated aging & $300 \times 70 \times 18$ & 5 & \\
\hline Mechanical & Internal bonding & $50 \times 50 \times 18$ & 15 & EN 319 [37] \\
properties & Three-point bending & $300 \times 36 \times 18$ & 15 & EN 310 [38] \\
\hline
\end{tabular}

Moisture content and density were measured on samples after conditioning in each climatic condition. Samples were considered to be acclimatized when the differences were smaller than the $0.1 \%$ mass of the sample between two weightings within $24 \mathrm{~h}$.

\subsection{Experimental}

\subsubsection{Dimensional Changes}

The relative changes in length and thickness of the samples were determined in between two equilibrium conditions. The increases in length and thickness due to swelling were measured from $65 \%$ to $85 \% \mathrm{RH}$ in adsorption (first regime), while the reductions in length and thickness due to shrinkage 
were measured from $65 \%$ to $35 \% \mathrm{RH}$ in desorption (second regime), according to the standard EN 318 [35]. The samples were exposed to different RH levels until acclimatized at two regimes. The first regime consisted of dimensional changes among consecutive RHs $35 \%, 65 \%$ and $85 \%$ at $20{ }^{\circ} \mathrm{C}$ constant temperature, whilst the second regime consisted of consecutive RHs in the reverse order, i.e., $85 \%, 65 \%$ and $35 \%$, at $20^{\circ} \mathrm{C}$ constant temperature.

Relative expansion and contraction sample's length were calculated using the formulae below:

$$
\begin{aligned}
& \delta l_{65,85}(\mathrm{~mm} / \mathrm{m})=1000 \times\left(l_{85}-l_{65}\right) / l_{65} \\
& \delta l_{65,35}(\mathrm{~mm} / \mathrm{m})=1000 \times\left(l_{35}-l_{65}\right) / l_{65}
\end{aligned}
$$

where $\delta l_{65,85}(\mathrm{~mm} / \mathrm{m})$ is the relative increase in length due to swelling of sample's length after RH change from $65 \%$ to $85 \%$, based on the length $l(\mathrm{~mm})$ measured at $65 \% \mathrm{RH}$ and $85 \% \mathrm{RH} ; 8 l_{65,35}(\mathrm{~mm} / \mathrm{m})$ is the relative reduction in thickness due to the shrinkage sample's length after RH change from $65 \%$ to $35 \%$, based on the length $l(\mathrm{~mm})$ measured at $65 \% \mathrm{RH}$ and $35 \% \mathrm{RH}$.

Similar to the calculations of relative change in the sample's length, thickness swelling and shrinkage properties were calculated as follows:

$$
\begin{aligned}
& \delta t_{65,85}(\%)=100 \times\left(t_{85}-t_{65}\right) / t_{65} \\
& \delta t_{65,35}(\%)=100 \times\left(t_{35}-t_{65}\right) / t_{65}
\end{aligned}
$$

where $\delta t_{65,85}(\%)$ is the relative increase in sample's thickness due to swelling after RH change from $65 \%$ to $85 \%$, based on the thickness $t(\mathrm{~mm})$ measured at $65 \% \mathrm{RH}$ and $85 \% \mathrm{RH} ; \delta t_{65,35}(\%)$ is the reduction of the sample's thickness due to shrinkage after RH change from $65 \%$ to $35 \%$, based on the thickness $t$ (mm) measured at $65 \% \mathrm{RH}$ and $35 \% \mathrm{RH}$.

\subsubsection{Thickness Swelling}

In this test, conditioned samples at $20^{\circ} \mathrm{C}$ and $65 \% \mathrm{RH}$ were placed in swelling testers (IMAL SW 200, San Damaso, Italy) having water $\mathrm{pH}$ of $7 \pm 1$, and the temperature was controlled to $20 \pm 1{ }^{\circ} \mathrm{C}$. Samples were immersed about $25 \mathrm{~mm}$ in water and were separated from each other and from the sides of the water bath. After immersion in water for $24 \mathrm{~h}$, the thickness of each test piece was measured by a digital caliper nearest to $0.01 \mathrm{~mm}$. Thickness swelling, $G_{t}(\%)$, was calculated based on the initial thickness $t_{1}(\mathrm{~mm})$ before and final thickness $t_{2}(\mathrm{~mm})$ after soaking in water.

$$
G_{t}=100 \times\left(t_{2}-t_{1}\right) / t_{1}
$$

\subsubsection{Accelerated Aging Test}

All the edges of the samples were coated with silicone resin, conditioned at $20{ }^{\circ} \mathrm{C}$ and $65 \% \mathrm{RH}$ and were placed in an QUV Accelerated Weathering Tester, QUV/spray (Q-Lab Co., Westlake, NJ, USA). This QUV with AUTOCAL system facilitates testing the external performance of products on their weather ability, light stability or corrosion resistance by simulating sunlight, rain and dew. The test was continued for $426 \mathrm{~h}$ and each complete cycle was equal to one week $(168 \mathrm{~h})$ following the sequence of condensation at $45^{\circ} \mathrm{C}$ for under $24 \mathrm{~h}$, a repeat of UV-radiation $60^{\circ} \mathrm{C}\left(0.89 \mathrm{~W} / \mathrm{m}^{2} / \mathrm{nm}\right)$ at a wavelength of $340 \mathrm{~nm}$ for under $2.5 \mathrm{~h}$ and water spray $(6-7 \mathrm{~L} / \mathrm{min})$ for under $0.5 \mathrm{~h}$. One complete cycle was equal to one week $(168 \mathrm{~h})$. Commercial MDF of similar thickness $(18 \mathrm{~mm})$ intended for indoor use was used for comparison.

\subsubsection{Non-Destructive Testing}

An acoustic resonance method was used for measuring the dynamic modulus of elasticity $\left(\mathrm{MOE}_{\mathrm{dyn}}\right)$. In this method, a data acquisition logger (PicoScope 4224, Cambridgeshire, UK) connected with the software BING ${ }^{\circledR}$, version 9.7.2 (Beam Identification by Non-destructive Grading by CIRAD- 
French Agricultural Research Centre for International Development, Montpellier, France) that controls, processes data and delivers results. A free-free flexural vibration test set-up was used, and more details about this method can be found in [39]. In flexural vibration, the first four modes of vibration were measured and used for determining the dynamic transversal modulus of elasticity, which represents stiffness under bending stress, i.e., $\mathrm{MOE}_{\mathrm{dyn}}$. The test was repeated four times for every sample, two times in each side, and the average was calculated.

\subsubsection{Static Bending Test}

A three-point bending test was performed to determine the static modulus of elasticity ( $\left.\mathrm{MOE}_{\text {stat }}\right)$ and modulus of rupture ( $\mathrm{MOR}_{\text {stat }}$ ) of the MDF samples following the standard EN 310 [38]. A universal testing machine (Instron 4466, Buckinghamshire, UK) with $10 \mathrm{kN}$ load capacity was used. A static bending test was performed on the same sample used for measuring $\mathrm{MOE}_{\mathrm{dyn}}$ in nondestructive testing. Uniaxial load was applied on the flat side of the samples. The load was constant $(10 \mathrm{~mm} / \mathrm{m})$ so that the maximum load was reached within $60 \pm 30 \mathrm{~s}$. An increment of load and deflection between $10 \%$ and $40 \%$ of maximum load was considered for measuring the $\mathrm{MOE}_{\text {stat }}(\mathrm{MPa})$.

$$
M O E_{\text {stat }}(M P a)=\left\{l^{3}\left(F_{2}-F_{1}\right)\right\} /\left\{4 b t^{3}\left(a_{2}-a_{1}\right)\right\}
$$

where $l$ is the span length $(\mathrm{mm}), b$ is the width of sample $(\mathrm{mm}), t$ is the thickness of sample $(\mathrm{mm}), F_{1}$ and $F_{2}$ are the increment of load at $10 \%$ and $40 \%$ of maximum load, and $a_{1}$ and $a_{2}$ are the corresponding deflection at the mid-length of the test pieces due to the load $F_{1}$ and $F_{2}$, respectively.

Bending strength, $\mathrm{MOR}_{\text {stat }}(\mathrm{MPa})$, of the test sample was calculated from the maximum load, $F_{\max }$ $(\mathrm{N})$, using the equation:

$$
\operatorname{MOR}_{\text {stat }}(\mathrm{MPa})=\left(3 F_{\max } l\right) /\left(2 b t^{2}\right)
$$

\subsubsection{Internal Bond Test}

Internal bond (IB) or tensile strength perpendicular to the plane of panels was measured following the standard EN 319 [37]. Samples were effectively bonded with a hot-melt glue, and tensile load was applied until rupture using an Instron 4466 universal testing machine (Buckinghamshire, England) with $10 \mathrm{kN}$ load capacity. A loading speed of $8 \mathrm{~mm} / \mathrm{min}$ was maintained so that the maximum load is reached within $60 \pm 30 \mathrm{~s}$. In addition to the conditioned samples at dry $\left(20^{\circ} \mathrm{C}, 35 \% \mathrm{RH}\right)$, standard $(20$ $\left.{ }^{\circ} \mathrm{C}, 65 \% \mathrm{RH}\right)$ and wet $\left(20{ }^{\circ} \mathrm{C}, 85 \% \mathrm{RH}\right)$ conditions, IB strength was also measured on samples after accelerated aging. IB or tensile strength (MPa) perpendicular to the plane of MDF test pieces was calculated by following the formula:

$$
\text { IB strength }(\mathrm{MPa})=F_{\max } /(a b)
$$

where $F_{\max }$ is the breaking load $(\mathrm{N})$, and $a$ and $b$ are the width $(\mathrm{mm})$ and length $(\mathrm{mm})$ of the test pieces, respectively.

\subsubsection{Finite Element Analysis}

Geometries of finite element (FE) models were identical to the samples manufactured for three-point bending tests and solved as a 3D problem; thus, full models were considered. Specifically, the beam's part was $300 \mathrm{~mm}$ in length, $36 \mathrm{~mm}$ in width with a thickness of $18 \mathrm{~mm}$, and the cylindrical pins' parts were $36 \mathrm{~mm}$ long with a diameter of $30 \mathrm{~mm}$ and placed $26 \mathrm{~mm}$ from both ends on a lower side of the beam part and in the middle of the beam's span on an upper side of the beam part. The beam part was created as a deformable body and pins as discrete rigid bodies. The boundary conditions (BCs) and load were applied to the reference points (RP) created on pins' circular areas. Six degrees of freedom (df) were fixed in both bottom pins' reference points for applying BCs and five df were set on the upper pin RP that also serves for applying a load. Namely, the following BCs were assigned: all six $\mathrm{df}$ are 
fastened, thus $1,2,3,4,5,6=0$ for pins at the ends on the lower side of the beam part; for the pin in the middle of the span on the upper side of the beam part movement in the $z$-axis direction was enabled, only five $\mathrm{df}$ are fastened allowing movement in direction 3 , thus $1,2,4,5,6=0$. The global coordinate system and $\mathrm{df}$ notations and plus directions are shown in Figure 1. The load applied to the beam was a concentrated nodal force of value $1200 \mathrm{~N}$, thus, larger than a mean value of the breaking load $\mathrm{F}_{\max }$ measured in the experiment (Figure 1).

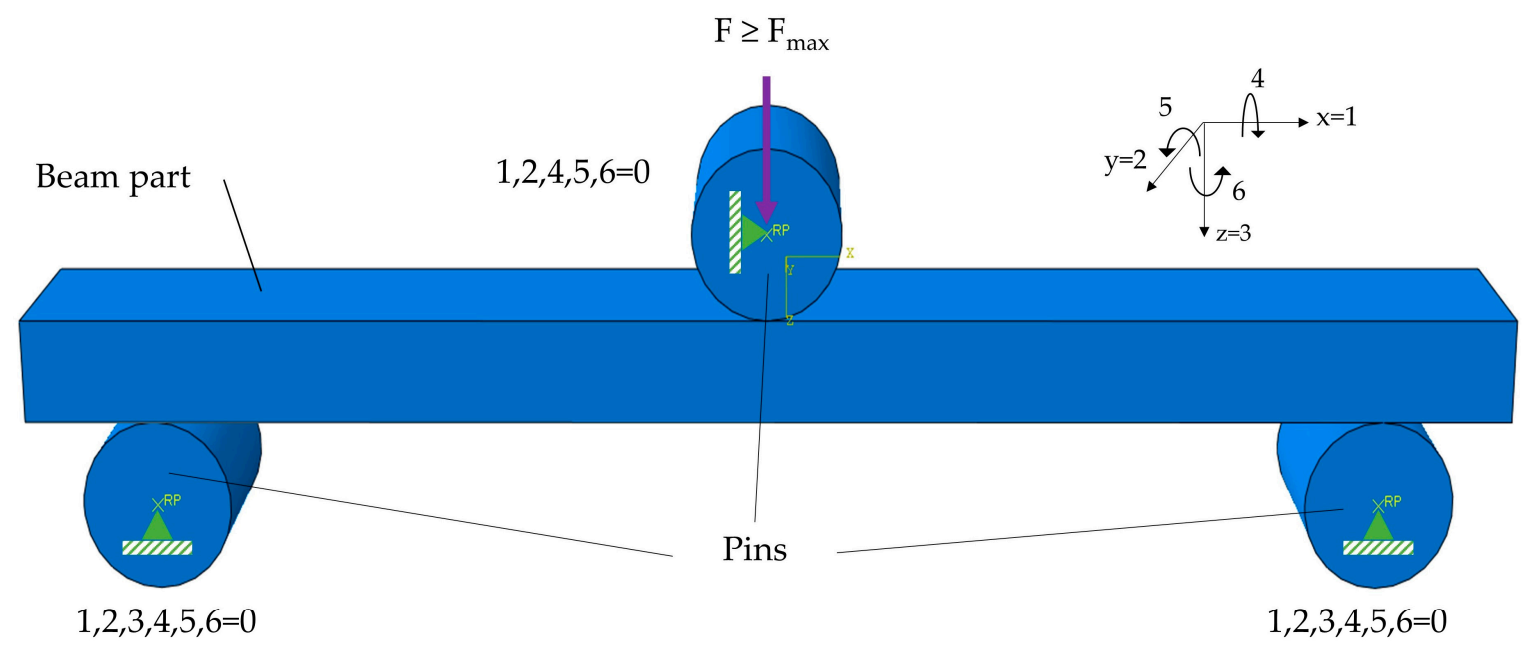

Figure 1. Illustration of parts and boundary conditions assigned in the finite element (FE) model.

$3 \mathrm{D}$ rigid elements $R 3 D 4$ (4-node bilinear quadrilateral) and R3D3 (3-node triangular facet) were assigned to mesh pins. To create a mesh for the beam, C3D8R (8-node linear brick) solid elements with reduced integration were defined.

Normal hard-contact, frictionless tangential behavior, and a general standard surface-to-surface contact, were prescribed to characterize the interaction between pin parts and the beam part. The mechanical properties of the elastic-plastic isotropic material of the studied MDFs had been taken from the experimental data considering the $\mathrm{RH}$ of $65 \%$ for the standard board perpendicular to bending: thus. Young's modulus of $2574 \mathrm{MPa}$, Poisson's ratio 0.25 , and density of $746.2 \mathrm{~kg} / \mathrm{m}^{3}$.

Additionally, to specify a damage initiation, damage criteria for the XFEM model were prescribed to define the constitutive response for cohesive elements: namely, the maximum principal stress damage criterion (MAXPS) of value $34.47 \mathrm{MPa}$, taken from experiment measures. This means the damage criterion is using traction separation laws and is established as:

$$
\mathrm{f}=\left\{\left\langle\sigma_{\max }\right\rangle / \sigma_{\max }^{0}\right\}
$$

where $\sigma^{0}{ }_{\max }$ represents the maximum allowable principal stress, and the symbol \langle\rangle represents the Macaulay bracket with the usual interpretation. The Macaulay brackets are here to represent that a purely compressive stress does not initiate damage; rather, damage is initiated when the maximum nominal stress ratio reaches a value of one $(f=1)$ [28]. Additionally, there was no initial crack assigned to the model. Instead, the XFEM crack domain was designated on the whole beam part. For describing a crack geometry and the crack's growth motion in 3D space, two level sets for a crack is assumed. First set is the crack surface $\Phi$ while second, $\Psi$, is made so the intersection of two level sets that gives the crack front. The nodal value of the function $\Phi$ is the signed distance of the node from the crack face and of the function $\Psi$ is the signed distance of the node from an almost-orthogonal surface passing through the crack front [28]. 


\subsubsection{Statistical Analysis}

To determine any statistically significant differences between // and $\perp$ samples, mean values were compared by a two-tailed group t-test at 0.05 significance level. In addition, to define relationships between measured parameters (MOE $\mathrm{E}_{\text {stat }}$ and $\mathrm{MOR}_{\text {stat }}, \mathrm{MOR}_{\text {stat }}$ and IB), linear regression analyses were performed.

Prediction models for $\mathrm{MOE}_{\text {stat }}$ and $\mathrm{MOR}_{\text {stat }}$ by using $\mathrm{MOE}_{\mathrm{dyn}}$ and $\mathrm{RH}$ as input variables were built from multiple regression analysis using the following equation:

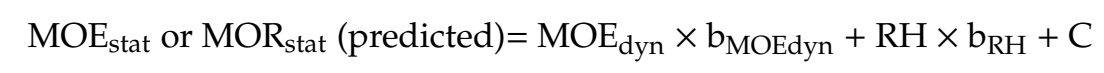

where $b$ is coefficient and $C$ is the intercept.

All regressions (linear, multiple) were performed at 95\% confidence level using the Microsoft Excel 365 program (Microsoft, Redmond, WA, USA). In addition, the ANOVA is used to check the adequacy of the regression model developed.

\section{Results and Discussion}

\subsection{Physical Properties}

Moisture content, density and thickness swelling of commercially produced Medite Tricoya ${ }^{\circledR}$ MDF samples at three different RH levels are presented in Table 2. As expected, the EMC and density of samples increased with an increase in RH levels. Medite Tricoya ${ }^{\circledR}$ samples had $48 \%$ lower equilibrium moisture content when compared with commercial indoor MDF samples of similar thickness (Li et al., unpublished data) at $85 \%$ RH. Similar results can be found in a previous work [17]. As the acetylation process is a single site reaction, which means that one acetyl group is attached to one hydroxyl group resulting in a reduction of moisture absorption sites in wood polymers [40], acetylated MDF panels have low EMC even at high humidity level. Only 7.1\% thickness swelling (after soaking in water for $24 \mathrm{~h}$ ) was observed, meaning that acetylated panels do not swell severely when they are exposed to the water. These results showed that acetylation plays a significant role in the thickness swelling of the Medite Tricoya ${ }^{\circledR}$ samples. However, the extent of the reduced thickness swelling of acetylated MDF depends on the weight percent gain levels by acetylation process [2].

Table 2. Physical properties of Medite Tricoya ${ }^{\circledR}$ MDF samples at different RH levels. Values in parenthesis are the standard deviations.

\begin{tabular}{cccc}
\hline Properties & $\mathbf{3 5 \%} \mathbf{R H}$ & $\mathbf{6 5 \%} \mathbf{R H}$ & $\mathbf{8 5 \%} \mathbf{R H}$ \\
\hline EMC $(\%)$ & $4.6(0.14)$ & $7.6(0.14)$ & $7.9(0.12)$ \\
Density $\left(\mathrm{kg} / \mathrm{m}^{3}\right)$ & $729.2(9.59)$ & $739.6(1.37)$ & $742.3(7.51)$ \\
\hline Thickness swelling $(\%)$ * & & $7.1(0.36)$ & \\
\hline
\end{tabular}

* Thickness swelling is measured after immersion in water for $24 \mathrm{~h}$ at $20{ }^{\circ} \mathrm{C}$.

Concerning the results of dimensional changes, the acetylation caused the MDF panels to absorb little moisture during the conditioning and are thus dimensionally stable (Table 3). The linear expansion of sample length and thickness swelling values obtained in adsorption conditions (relative humidity change from $65 \%$ to $85 \%$ ) were higher than those values obtained in desorption conditions (relative humidity change from $65 \%$ to $35 \%$ ). The amount of water held by wood fibers at a given temperature and RH depends on the direction from which equilibrium is approached. The moisture adsorbed at high relative humidity exposure is not entirely released when re-drying by lowering the relative humidity levels, and this phenomenon was well observed for wood-based panels in other studies [41,42]. As a result, acetylation had a major effect on the dimensional stability of Medite Tricoya ${ }^{\circledR}$ samples. In addition, the density of panels can also adversely affect the dimensional stability [41]. Average linear expansion and retraction of Medite Tricoya ${ }^{\circledR}$ samples were, respectively, $23 \%$ and $57 \%$ lower than 
those of standard samples (Li et al., unpublished data) and for thickness changes, those differences were $67 \%$ and $45 \%$ (comparison was done from Li et al., unpublished data). However, no significant differences of relative shrinkage or swelling in thickness and length were observed in the two principle directions (// and $\perp$ direction of sanding). An exception was seen for the relative swelling in length when $\mathrm{RH}$ increased from $65 \%$ to $85 \%$ where swelling was significantly higher in perpendicular samples. However, the reason for that is not quite clear.

Table 3. Relative changes in thickness and length of Medite Tricoya ${ }^{\circledR}$ MDF sample at different relative humidity $(\mathrm{RH})$ levels. Values in parenthesis are the standard deviations.

\begin{tabular}{cccc}
\hline \multirow{2}{*}{ Properties } & \multirow{2}{*}{ Direction } & \multicolumn{2}{c}{ Relative Change } \\
\cline { 3 - 4 } & & $\delta_{65,35}$ & $\delta_{65,85}$ \\
\hline \multirow{2}{*}{ Thickness (\%) } & $/$ & $-1.12(0.08)$ & $1.44(0.07)$ \\
& $\perp$ & $-1.17(0.07)$ & $1.36(0.03)$ \\
\hline$t$-value & & $-0.905^{\mathrm{NS}}$ & $-2.140^{\mathrm{NS}}$ \\
\hline \multirow{2}{*}{ Length $(\mathrm{mm} / \mathrm{m})$} & $\perp$ & $-0.34(0.03)$ & $0.58(0.08)$ \\
& $\perp$ & $-0.44(0.09)$ & $0.68(0.03)$ \\
\hline$t$-value & & $-1.819^{\mathrm{NS}}$ & $3.624^{*}$ \\
\hline
\end{tabular}

//: parallel sample to the sanding direction; $\perp$ : perpendicular sample to the sanding direction; $\delta_{65,35}$ : samples conditioned from $65 \%$ to $35 \%$ RH; $\delta_{65,85}$ : samples conditioned from $65 \%$ to $85 \% \mathrm{RH}$. * Significant at the 0.05 level as determined by two-sample t-test. NS, non-significant.

\subsection{Mechanical Properties}

Table 4 shows $\mathrm{MOE}_{\text {stat }}, \mathrm{MOR}_{\text {stat }}$ and IB properties of parallel and perpendicular samples from Medite Tricoya ${ }^{\circledR}$ MDF conditioned at dry, standard and wet conditions. With the increase of RH from 35 to $65 \%$, the average $\mathrm{MOE}_{\text {stat }}$ and $\mathrm{MOR}_{\text {stat }}$ reduction of Medite Tricoya ${ }^{\circledR}$ samples was $8 \%$ and $10 \%$, respectively. When the RH was further raised from $65 \%$ to $85 \%$, reduction of those properties was respectively $37 \%$ and $20 \%$. Higher humidity environment had a detrimental effect on the $\mathrm{MOE}_{\text {stat }}$ and $\mathrm{MOR}_{\text {stat }}$ and IB strength values for both sample types.

Table 4. Static bending properties and internal bond (IB) strength of Medite Tricoya ${ }^{\circledR}$ MDF samples. Values in parentheses are the standard deviations.

\begin{tabular}{|c|c|c|c|c|c|c|c|c|c|}
\hline \multirow[b]{2}{*}{ Direction } & \multicolumn{3}{|c|}{ Dry, 35\% RH } & \multicolumn{3}{|c|}{ Standard, $65 \% \mathrm{RH}$} & \multicolumn{3}{|c|}{ Wet, 85\% RH } \\
\hline & $\begin{array}{c}\text { IB } \\
\text { Strength } \\
\text { [MPa] }\end{array}$ & $\begin{array}{c}\mathrm{MOE}_{\text {stat }} \\
{[\mathrm{MPa}]}\end{array}$ & $\begin{array}{c}\text { MOR }_{\text {stat }} \\
\text { [MPa] }\end{array}$ & $\begin{array}{c}\text { IB } \\
\text { Strength } \\
\text { [MPa] }\end{array}$ & $\begin{array}{c}\mathrm{MOE}_{\text {stat }} \\
\text { [MPa] }\end{array}$ & $\begin{array}{c}\text { MOR }_{\text {stat }} \\
\text { [MPa] }\end{array}$ & $\begin{array}{c}\text { IB } \\
\text { Strength } \\
\text { [MPa] }\end{array}$ & $\begin{array}{c}\mathrm{MOE}_{\text {stat }} \\
\text { [MPa] }\end{array}$ & $\begin{array}{c}\mathrm{MOR}_{\text {stat }} \\
{[\mathrm{MPa}]}\end{array}$ \\
\hline // & \multirow{2}{*}{$\begin{array}{c}0.99 \\
( \pm 0.08)\end{array}$} & $\begin{array}{c}2938 \\
( \pm 43.38)\end{array}$ & $\begin{array}{c}38.64 \\
( \pm 0.65) \\
\end{array}$ & \multirow{2}{*}{$\begin{array}{c}0.79 \\
( \pm 0.10)\end{array}$} & $\begin{array}{c}2670 \\
( \pm 61.28)\end{array}$ & $\begin{array}{c}33.95 \\
( \pm 0.81)\end{array}$ & \multirow{2}{*}{$\begin{array}{c}0.57 \\
( \pm 0.07)\end{array}$} & $\begin{array}{c}1656 \\
( \pm 46.94)\end{array}$ & $\begin{array}{c}26.80 \\
( \pm 0.97)\end{array}$ \\
\hline$\perp$ & & $\begin{array}{c}2759 \\
( \pm 66.47)\end{array}$ & $\begin{array}{c}35.73 \\
( \pm 0.99) \\
\end{array}$ & & $\begin{array}{c}2557 \\
( \pm 76.30) \\
\end{array}$ & $\begin{array}{c}33.25 \\
( \pm 0.49) \\
\end{array}$ & & $\begin{array}{c}1628 \\
( \pm 46.40)\end{array}$ & $\begin{array}{c}26.77 \\
( \pm 0.63)\end{array}$ \\
\hline$t$-value & & $4.516^{*}$ & $4.906 *$ & & $2.306^{*}$ & $1.460 \mathrm{NS}$ & & $0.841^{\mathrm{NS}}$ & $0.044^{\mathrm{NS}}$ \\
\hline
\end{tabular}

//: parallel sample to the sanding direction; $\perp$ : perpendicular sample to the sanding direction. ${ }^{*}$ Significant at the 0.05 level as determine by two-sample T test. NS, non-significant.

Mechanical properties like $\mathrm{MOE}_{\text {stat }}$ and $\mathrm{MOR}_{\text {stat }}$ measure the elastic behavior and resistance to bending, respectively, and are important properties when MDF is placed under load. Aforementioned properties determine largely the applicability of MDF as a structural component in furniture or other constructions. Those properties also depend on the sample properties, i.e., sanding direction (parallel or perpendicular), density, moisture content and type of MDF [2,5,43]. Dimensional stability is a good indication of the acetylation effect. However, moisture content had a great influence on the strength properties of both types of MDF samples. Significant reductions in $\mathrm{MOE}_{\text {stat }}, \mathrm{MOR}_{\text {stat }}$ and IB strength values were observed with an increase in RH (Table 4). These findings are in agreement with the 
results found in previous studies [2,43]. The decrease in such properties at increasing RH level can be attributed to the separation of fibers resulting from the thickness swell of the panel materials [44]. Differences in the static bending properties were also found between parallel and perpendicular samples, and especially at the dry condition these differences were statistically significant. In general, $\mathrm{MOE}_{\text {stat }}$ and $\mathrm{MOR}_{\text {stat }}$ values were higher in parallel samples compared to perpendicular samples (see Table 4). Lower bending strength and stiffness values of perpendicular samples in MDF and other wood-based panels have been reported previously [26].

Figure 2 shows the linear regressions that determine how well the $\mathrm{MOR}_{\text {stat }}$ are related with $\mathrm{MOE}_{\text {stat }}$ values in parallel and perpendicular samples at different humid conditions. Statistical analysis showed strong positive and significant relationships $(p<0.05)$ for both sample directions (parallel and perpendicular) at varying humidity levels. Strong correlation between bending strength and modulus of elasticity is known for wood-based panels [45]. When linear regression analyses were performed by separating humid condition, very poor and insignificant relationships were observed. In the parallel samples, the coefficients of determination $\left(\mathrm{R}^{2}\right)$ were 0.08 and 0.39 at $65 \%$ and $85 \% \mathrm{RH}$, respectively; whilst in the perpendicular samples, those values were, respectively, 0.20 and 0.25 . However, in a dry condition $(35 \% \mathrm{RH})$, significant relationships $(p<0.05)$ were observed, and $\mathrm{R}^{2}$ values were 0.85 and 0.88 in parallel and perpendicular samples, respectively. Previous findings also showed higher correlation coefficients at lower moisture content levels for wood-based panels [46,47].
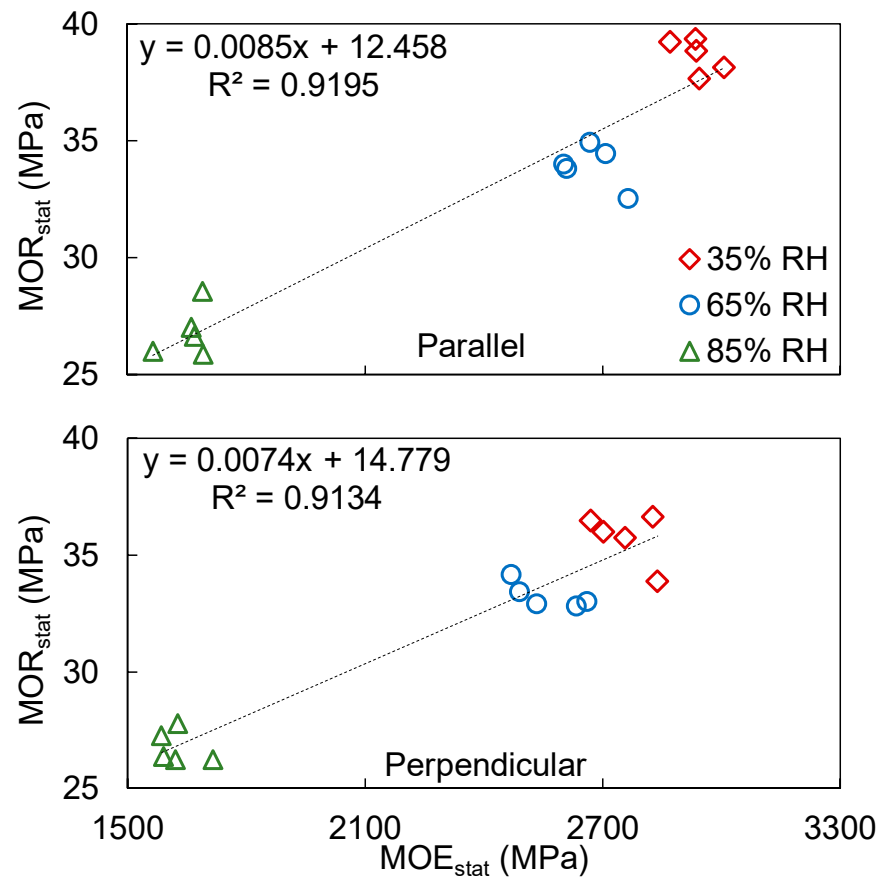

Figure 2. Linear relationship between $\mathrm{MOE}_{\text {stat }}$ and $\mathrm{MOR}_{\text {stat }}$ of the Medite Tricoya ${ }^{\circledR}$ medium density fiberboard (MDF) samples in two different directions conditioned at three different climatic conditions.

A positive and significant relationship $(p<0.05)$ between $\mathrm{MOR}_{\text {stat }}$ and IB was also observed (Figure 3). As shown in Table 4, Medite Tricoya ${ }^{\circledR}$ samples had the highest IB strength at $35 \%$ RH. With the increase of RH from 35 to $65 \%$, the average IB strength reduction of Medite Tricoya ${ }^{\circledR}$ samples was $20 \%$. When the RH was further raised from $65 \%$ to $85 \%$, reduction of IB strength was $27 \%$.

UV radiation causes photochemical degradation mainly in lignin polymers of the cell walls. UV light in combination with water plays a major role in such type of weathering. When lignin is degraded, water washes away degraded products and subsequently loosens the surface fibers to erode. However, acetylation reduces the loss of surface lignin and thus the erosion caused by accelerated weathering [48]. When compared with commercial MDF samples (indoor use), Medite Tricoya ${ }^{\circledR}$ samples performed much better in terms of the extent of being weathered by moisture and UV light. Thickness swelling 
of the test pieces from indoor MDF was almost twice as much as Medite Tricoya ${ }^{\circledR}$ (Figure 4). After the accelerated aging test, fibers in the indoor samples were separated and were possible to shred by finger rub. That implied that no residual strength was left. Medite Tricoya ${ }^{\circledR}$ samples showed better resistance against thickness swelling. This could be attributed to the fiber-fiber bonding efficacy of the resin to retain bonding in a very hydrophobic fiber network. After accelerated aging and conditioning $\left(20^{\circ} \mathrm{C}, 65 \% \mathrm{RH}\right)$, the IB strength of the Medite Tricoya ${ }^{\circledR}$ samples was found to be $0.79 \pm 0.06 \mathrm{MPa}$. This result showed that Medite Tricoya ${ }^{\circledR}$ samples made from acetylated wood fibers were able to retain the initial IB strength of non-weathered samples. Previous results also showed that a higher residual strength was observed in acetylated MDF after a cyclic test [19]. Such retention of strength can also be attributed to other parameters than the acetylation of fibers, such as the adhesive used [49].

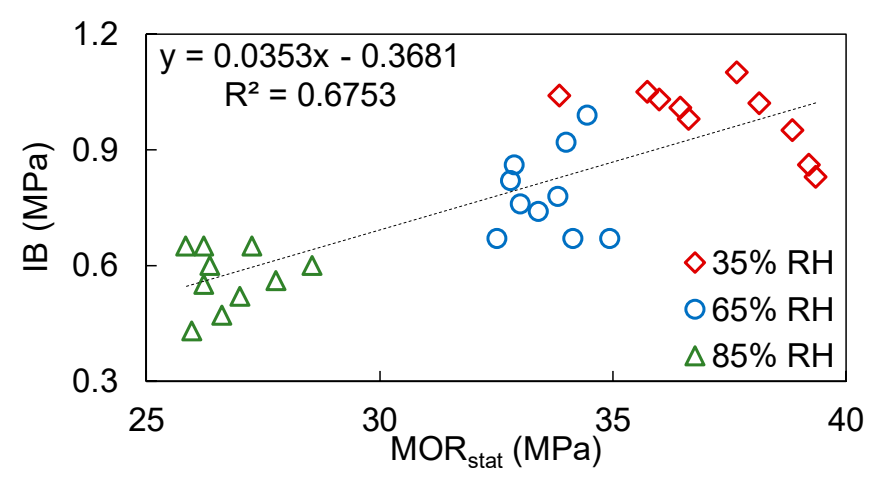

Figure 3. Linear relationship between $\mathrm{MOR}_{\text {stat }}$ and internal bond (IB) strength of the Medite Tricoya ${ }^{\circledR}$ MDF samples conditioned at three different humidity.

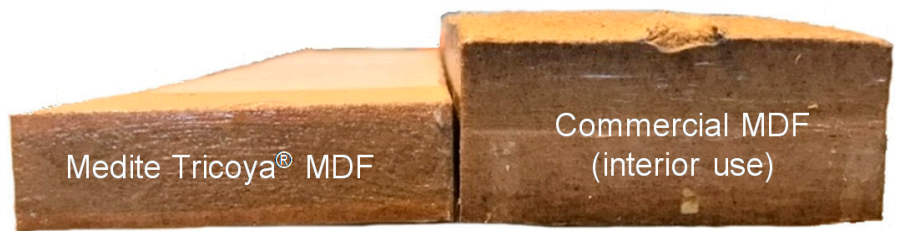

Figure 4. Medite Tricoya ${ }^{\circledR}$ and commercial standard MDF (for interior use) samples after accelerated aging test. Note the double thickness in the commercial MDF sample.

Acoustic resonance measurements were used to determine the $\mathrm{MOE}_{\text {dyn }}$ (Figure 5). These values represent the mean stiffness, whilst $\mathrm{MOE}_{\text {stat }}$ represents the local stiffness of the samples at the highly stressed areas of a specific test set-up [50]. $\mathrm{MOE}_{\text {dyn }}$ was found to differ significantly between $/ /$ and $\perp$ samples only for the dry condition, i.e., $35 \%$ RH. As expected, the increase of RH from dry/standard ( 35 and $65 \% \mathrm{RH}$ ) to wet $\left(85 \% \mathrm{RH}\right.$ ) conditions resulted in a considerable decrease in $\mathrm{MOE}_{\text {dyn }}$ in both directions.Resonance frequency of MDF samples decreased with the increase in moisture content and thus affected the $\mathrm{MOE}_{\mathrm{dyn}}$. This is because at a dryer state, molecular chains in the amorphous regions of the wood cell wall are distorted with the presence of microvoids between the molecular chains, resulting in lower internal friction, resulting in higher $\mathrm{MOE}_{\mathrm{dyn}}$. On the contrary, when moisture content increases, water molecules are embedded in the microvoids and rearrange the distorted molecular chains in the amorphous region. If the moisture content increases further, water acts as a plasticizer and decreases the cohesive forces between molecules, resulting in a higher internal friction and leading to the decrease in $\mathrm{MOE}_{\text {dyn }}$ [51]. With the increase of $\mathrm{RH}$ from 35 to $65 \%$, the average $\mathrm{MOE}_{\text {dyn }}$ reduction of Medite Tricoya ${ }^{\circledR}$ samples was negligible, i.e., $1 \%$. When the RH was further raised from $65 \%$ to $85 \%$, the reduction of $\mathrm{MOE}_{\text {dyn }}$ was $26 \%$. In addition, $\mathrm{MOE}_{\text {dyn }}$ values in the perpendicular samples were found lower than the corresponding values in the parallel samples. However, those differences were found to be statistically insignificant. A previous study by Han et al. [26] showed that reduction of stress wave velocity along the perpendicular direction compared to the parallel direction for wood-based panels (plywood, oriented strand board and particleboard) depends on the anisotropic properties 
of the products. Smaller differences between the two directions in MDF samples implies a uniform product. However, as expected, $\mathrm{MOE}_{\mathrm{dyn}}$ values were higher than the static values approximately by $40 \%$. Wood-based panels contain a significant number of glued interfaces, and such a difference is generally explained by the different rates of stresses applied in the dynamic and static tests [52]. The differences between the $\mathrm{MOE}_{\mathrm{dyn}}$ and $\mathrm{MOE}_{\text {stat }}$ values were higher at a higher $\mathrm{RH}$. It was $33 \%, 37 \%$ and $49 \%$ higher at $35 \%, 65 \%$ and $85 \% \mathrm{RH}$ conditions, respectively. This is because moisture affects the stress-wave properties for wood-based panels, as they can swell considerably during moisture uptake. The swelling often leads to bond failures and to changes of their internal structure, and as a result, to a decrease of stress wave velocity with the increase in panel moisture content [26].

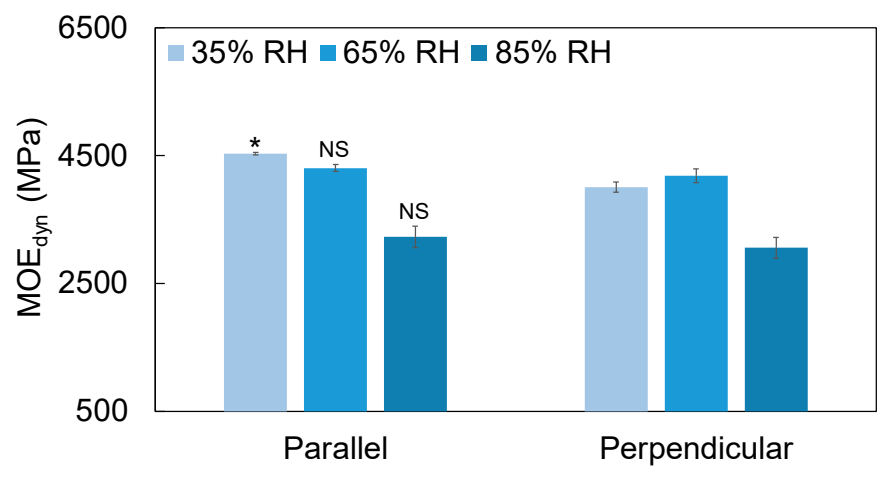

Figure 5. Dynamic modulus of elasticity $\left(\mathrm{MOE}_{\mathrm{dyn}}\right)$ of Medite Tricoya ${ }^{\circledR} \mathrm{MDF}$ samples at different relative humidity levels measured by the acoustic resonance method. Error bars represent $95 \%$ confidence intervals for the means. * Significant differences between parallel and perpendicular samples as determined by two-sample t-test at the 0.05 level. NS, non-significant.

Acoustic tools have been used quite successfully to predict $\mathrm{MOE}_{\text {stat }}$ and $\mathrm{MOR}_{\text {stat }}[26,27,53]$. Table 5 shows the multiple regression model summary results. Overall, linear and significant relationships $(p<0.05)$ of $\mathrm{MOE}_{\text {stat }}$ and $\mathrm{MOR}_{\text {stat }}$ with $\mathrm{MOE}_{\mathrm{dyn}}$ were observed at different humid conditions. It was noted that $R^{2}$ values were slightly higher between $M O E_{d y n}$ and $M O E_{\text {stat }}$ than those between $M O E_{d y n}$ and $\mathrm{MOR}_{\text {stat }}$.

Table 5. Model summary of regression statistics for $\mathrm{MOE}_{\text {stat }}$ and $\mathrm{MOR}_{\text {stat }}$ prediction.

\begin{tabular}{ccccc}
\hline \multirow{2}{*}{ Parameter } & \multicolumn{2}{c}{ MOE $_{\text {stat }}$} & \multicolumn{2}{c}{ MOR $_{\text {stat }}$} \\
\cline { 2 - 5 } & Parallel & Perpendicular & Parallel & Perpendicular \\
\hline $\mathrm{R}^{2}$ & 0.987 & 0.969 & 0.966 & 0.925 \\
Adjusted $\mathrm{R}^{2}$ & 0.970 & 0.964 & 0.960 & 0.913 \\
Standard error & 99.484 & 97.717 & 1.020 & 1.175 \\
Intercept & -412.519 & 883.65 & 26.822 & 28.071 \\
$\mathrm{RH}$ coefficient & -5.101 & -11.624 & -0.140 & -0.120 \\
MOE $_{\text {dyn coefficient }}$ & 0.784 & 0.573 & 0.004 & 0.003 \\
F & 227.009 & 187.664 & 169.889 & 74.404 \\
Significance F & 0.000 & 0.000 & 0.000 & 0.000 \\
\hline
\end{tabular}

* Significant at the 0.05 level.

The comparison between the experimental and predicted values is shown in Figure 6. The result indicates that the predicted values are very close to the experimental values. F-values for all models $\left(\mathrm{MOE}_{\text {stat }}\right.$ and $\mathrm{MOR}_{\text {stat }}$ in parallel and perpendicular samples) were highly significant at the 0.05 level (Table 5).

Statistical analysis showed that $\mathrm{MOE}_{\mathrm{dyn}}$ and $\mathrm{RH}$ can be used as predictors of $\mathrm{MOE}_{\text {stat }}$ and $\mathrm{MOR}_{\text {stat }}$ of MDF samples. The results also indicated that $\mathrm{MOE}_{\text {stat }}$ and $\mathrm{MOR}_{\text {stat }}$ have a positive relationship with $\mathrm{MOE}_{\mathrm{dyn}}$. 

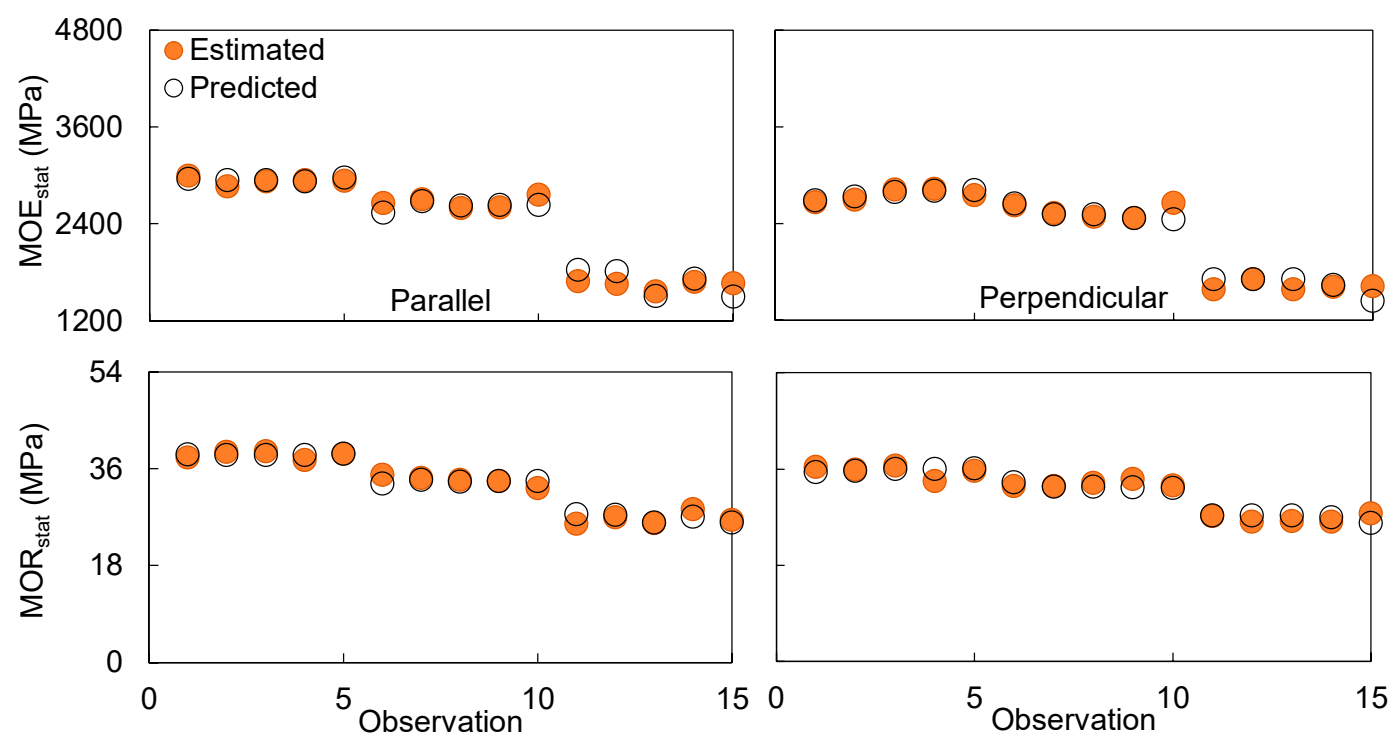

Figure 6. Estimated and predicted values of $\mathrm{MOE}_{\text {stat }}$ and $\mathrm{MOR}_{\text {stat }}$ for Medite Tricoya ${ }^{\circledR}$ MDF samples conditioned at three different climatic conditions.

\subsection{Finite Element Analysis}

Magnitudes of reaction forces and the deflections under these reactions forces in the z-axis direction, as well as values of maximal principal stress for $\mathrm{T} 1, \mathrm{~T} 2$ procedures and experimental values, are presented in Table 6. Reaction forces are equal to half of maximal loading force.

Table 6. Magnitudes of displacements, reaction forces, and maximal principal stress for first approach

(T1) and second approach (T2) finite element (FE) procedure, and experimental values.

\begin{tabular}{cccc}
\hline Procedure & $\begin{array}{c}\text { Displacement } \\
{[\mathbf{m m}]}\end{array}$ & $\begin{array}{c}\text { Reaction Force } \\
{[\mathbf{N}]}\end{array}$ & $\begin{array}{c}\text { Maximal Principal Stress } \\
{[\mathbf{M P a}]}\end{array}$ \\
\hline $\begin{array}{c}\text { T1-quasi- static stress } \\
\text { /displacement }\end{array}$ & 8.3 & 599 & 30.98 \\
\hline $\begin{array}{c}\text { T2-extended finite } \\
\text { element method }\end{array}$ & 8.9 & 641 & 35.60 \\
\hline Experimental value & 7.6 & 563 & 35.89 \\
\hline
\end{tabular}

Finally, it is necessary to add that the values for the T2 model show the maximal values at the time point when the jump in the damage dissipation energy occurs (Figure 7): thus, in this particular case, at the time increment 0.4623 of 1 with index number 30. At this time, the increment of the crack growth is initiated and the crack propagates [28], i.e., we are at beginning of a fracture mechanism.

The crack occurrence is visualized in Figure 8 using the PHILSM function, i.e., a singled distance function that describes the crack surface [28].

When we compare results obtained from the two computational models using different simulations techniques T1 (quasi-static stress/displacement) and T2 (extended finite element) with the experimental values, we see percental errors of $8.6 \%$ and $14.3 \%$. As expected, these percent errors are relatively high. This demonstrates that the used computational methods do not provide reliable results, and thus, can be considered to have a low fidelity. Despite this fact, these techniques are today used as the main techniques in standard design procedures because they are highly efficient [29,31]. To be sure, the errors can be minimized by optimizing the input parameters that imitate the real nature of the studied MDF material; however, that requires more necessary testing, like, for example, creep testing and fracture testing, to obtain those data. This means spending more time to set up experiments, more wasted material for creating samples, as well as time to collect and analyze data sets. 


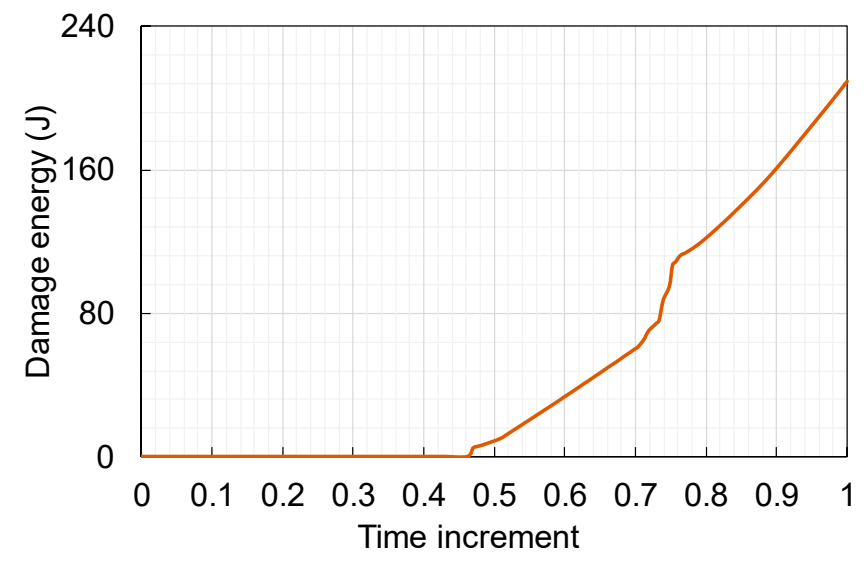

Figure 7. Damage dissipation energy for the extended finite element method model (T2).
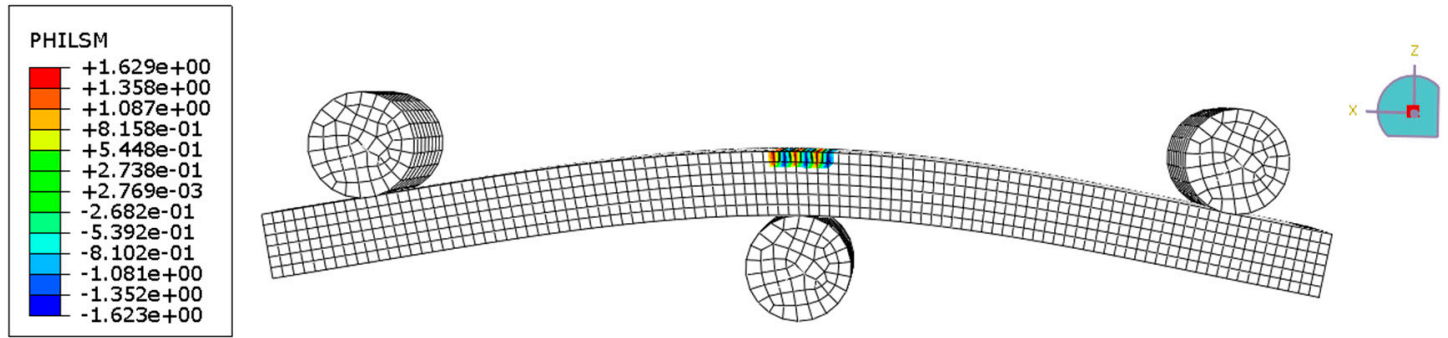

Figure 8. Singled distance function (PHILSM) for T2 model.

A better solution here is to use the help of micromechanical modelling approaches to specify material behaviour on a constituent level that is summarized in [32,54,55], and that will provide more reliable results compared with experimental ones and reduce the need for new sets of tests. More precisely, the employment of concurrent material and structural design applying multiscale models comes in since viscoelastic creep damage models and rheological behavior of MDF material are considered [56]. Here, we mean the time-dependent mechanical repose of MDF on a constant load considering the influence material's density as well as fiber orientation, and the existence of voids and interfaces in the material microstructure. More importantly, the macroscale computational techniques used in this work do not take into consideration the very significant dependence of mechanical properties on the moisture and temperature. This, as demonstrated in this work, should be included in the computations to precisely predict mechanical material characteristics such as strength, toughness and elasticity as well as to predict the damage mechanism of the panel product.

\section{Conclusions}

The results obtained in this study showed that, due to the lower hygroscopicity of Medite Tricoya ${ }^{\circledR}$ samples, they absorbed less moisture and became more dimensionally stable even at the highest humidity condition. This MDF type can also retain its IB strength after an accelerated aging test. However, IB strength, $\mathrm{MOE}_{\text {stat }}$ and $\mathrm{MOR}_{\text {stat }}$ were reduced from dry to humid conditions. At the highest humid condition ( $85 \% \mathrm{RH})$, strength and stiffness values did not differ significantly between parallel and perpendicular samples. In addition, multiple regression models were developed from $\mathrm{MOE}_{\text {dyn }}$ and RH to predict the strength and stiffness of Medite Tricoya ${ }^{\circledR}$ MDF. In both parallel and perpendicular directions, highly significant relationships were observed. Developed models could predict the $\mathrm{MOE}_{\text {stat }}$ and $M O R_{\text {stat }}$ values of Medite Tricoya ${ }^{\circledR}$ MDF samples at any humid conditions, which produced an excellent fit to the measured values. This experimental outcome could ensure reliable and safe predictions of Medite's Tricoya ${ }^{\circledR}$ MDF strength and stiffness properties for intended end uses. 
This study also showed that employing macroscale computational modelling approaches that are nowadays broadly used in engineering practice, such as quasi-static stress/displacement (T1) and extended finite element (T2) techniques, are not sufficient to obtain reliable results for MDF. These modelling methods are highly efficient and fast, but low in fidelity. Therefore, in future work, it is necessary to employ more precise multiscale models to secure more efficient material and structure design approaches. Additionally, multiscale models will reduce the necessity to set up new testing whenever we need to change the components proportion or component material in composite material.

Author Contributions: Conceptualization, S.A.A. and S.A.; methodology, S.A.A. and S.A.; software, S.A.A.; validation, S.A.A.; formal analysis, S.A.A. and J.K.; investigation, J.L.; data curation, J.L.; writing-original draft preparation, S.A.A. and J.K.; writing-review and editing, S.A.; visualization, S.A.A. and J.K.; supervision, S.A. All authors have read and agreed to the published version of the manuscript.

Funding: This research received no external funding.

Conflicts of Interest: The authors declare no conflict of interest.

\section{References}

1. Bianchi, S.; Thömen, H.; Junginger, S.; Pichelin, F. Medium density boards made of groundwood fibres: An analysis of their mechanical and physical properties. Eur. J. Wood Wood Prod. 2018, 77, 71-77. [CrossRef]

2. Ayrilmis, N.; Winandy, J.E. Effects of Post Heat-Treatment on Surface Characteristics and Adhesive Bonding Performance of Medium Density Fiberboard. Mater. Manuf. Process. 2009, 24, 594-599. [CrossRef]

3. Palardy, R.D.; Haataja, B.A.; Shaler, S.M.; Williams, A.D.; Laufenberg, T.L. Pressing of wood composite panels at moderate temperature and high moisture content. For. Prod. J. 1989, 39, 27-32.

4. Li, X.; Li, Y.; Zhong, Z.; Wang, D.; Ratto, J.A.; Sheng, K.; Sun, X.S. Mechanical and water soaking properties of medium density fiberboard with wood fiber and soybean protein adhesive. Bioresour. Technol. 2009, 100, 3556-3562. [CrossRef] [PubMed]

5. Mohebby, B.; Gorbani-Kokandeh, M.; Soltani, M. Springback in acetylated wood based composites. Constr. Build. Mater. 2009, 23, 3103-3106. [CrossRef]

6. Findley, W.N.; Lai, J.S.; Onaran, K. Creep and Relaxation of Nonlinear Viscoelastic Materials; North-Holland Publishing Company: New York, NY, USA, 1976.

7. Ji, X.; Li, B.; Yuan, B.; Guo, M. Preparation and characterizations of a chitosan-based medium-density fiberboard adhesive with high bonding strength and water resistance. Carbohydr. Polym. 2017, 176, $273-280$. [CrossRef] [PubMed]

8. Gao, S.; Liu, Y.; Wang, C.; Chu, F.; Xu, F.; Zhang, D. Synthesis of Lignin-Based Polyacid Catalyst and Its Utilization to Improve Water Resistance of Urea-formaldehyde Resins. Polymers 2020, 12, 175. [CrossRef]

9. Mamiński, M.Ł.; Trzepałka, A.; Auriga, R.; H’Ng, P.S.; Chin, K.L. Physical and mechanical properties of thin high density fiberboard bonded with 1,3-dimethylol-4,5-dihydroxyethyleneurea (DMDHEU). J. Adhes. 2020, 96, 679-690. [CrossRef]

10. Oliveira, S.L.; Freire, T.P.; Mendes, R.F. The Effect of Post-Heat Treatment in MDF Panels. Mater. Res. 2017, 20, 183-190. [CrossRef]

11. Garcia, R.A.; Cloutier, A.; Riedl, B. Dimensional stability of MDF panels produced from heat-treated fibres. Holzforschung 2006, 60, 278-284. [CrossRef]

12. Lee, T.C.; Mohd Pu'ad, N.A.S.; Selimin, M.A.; Manap, N.; Abdullah, H.Z.; Idris, M.I. An overview on development of environmental friendly medium density fibreboard. Mater. Today Proc. 2020, 29, 52-57. [CrossRef]

13. Dazmiri, M.K.; Kiamahalleh, M.V.; Kaiamahalleh, M.V.; Mansouri, H.R.; Moazami, V. Revealing the impacts of recycled urea-formaldehyde wastes on the physical-mechanical properties of MDF. Eur. J. Wood Wood Prod. 2018, 77, 293-299. [CrossRef]

14. Papadopoulos, A.N.; Gkaraveli, A. Dimensional stabilization and strength of particleboard by chemical modification with propionic anhydride. Holz Roh Werkst. 2003, 61, 142-144. [CrossRef]

15. Kajita, H.; Imamura, Y. Improvement of physical and biological properties of particleboards by impregnation with phenolic resin. Wood Sci. Technol. 1991, 26, 63-70. [CrossRef] 
16. Nasir, M.; Gupta, A.; Beg, M.D.H.; Chua, G.K.; Asim, M. Laccase application in medium density fibreboard to prepare a bio-composite. RSC Adv. 2014, 4, 11520-11527. [CrossRef]

17. Rowell, R.M.; Youngquist, J.A.; Rowell, J.S.; Hyatt, J.A. Dimensional stability of aspen fiberboard made from acetylated fiber. Wood Fiber Sci. 1991, 23, 558-566.

18. Mai, C.; Direske, M.; Varel, D.; Weber, A. Light medium-density fibreboards (MDFs): Does acetylation improve the physico-mechanical properties? Eur. J. Wood Wood Prod. 2016, 75, 739-745. [CrossRef]

19. Gomez-Bueso, J.; Westin, M.; Torgilsson, R.; Olesen, P.O.; Simonson, R. Composites made from acetylated lignocellulosic fibers of different origin-Part I. Properties of dry-formed fiberboards. Holz Roh Werkst. 2000, 58, 9-14. [CrossRef]

20. Mahlberg, R.; Paajanen, L.; Nurmi, A.; Kivisto, A.; Koskela, K.; Rowell, R.M. Effect of chemical modification of wood on the mechanical and adhesion properties of wood fiber/polypropylene fiber and polypropylene/veneer composites. Eur. J. Wood Wood Prod. 2001, 59, 319-326. [CrossRef]

21. Vick, C.B.; Krzysik, A.; Wood, J.E., Jr. Acetylated, isocyanate-bonded flakeboards after accelerated aging: Dimensional stability and mechanical properties. Holz Roh Werkst. 1991, 49, 221-228. [CrossRef]

22. Korai, H. Effects of low bondability of acetylated fibers on mechanical properties and dimensional stability of fiberboard. J. Wood Sci. 2001, 47, 430-436. [CrossRef]

23. Ghorbani, M.; Bavaneghi, F. Effect of Press Cycle Time on Application Behavior of Board Made from Chemically Modified Particles. Drv. Ind. 2016, 67, 25-31. [CrossRef]

24. Legg, M.; Bradley, S. Measurement of stiffness of standing trees and felled logs using acoustics: A review. J. Acoust. Soc. Am. 2016, 139, 588-604. [CrossRef]

25. Wang, X. Acoustic measurements on trees and logs: A review and analysis. Wood Sci. Technol. 2013, 47, 965-975. [CrossRef]

26. Han, G.; Wu, Q.; Wang, X. Stress-wave velocity of wood-based panels: Effect of moisture, product type, and material direction. For. Prod. J. 2006, 56, 28-33.

27. Guan, C.; Guan, C.; Zhou, L.; Wang, X. Dynamic determination of modulus of elasticity of full-size wood composite panels using a vibration method. Constr. Build. Mater. 2015, 100, 201-206. [CrossRef]

28. Dassault Systèmes. SIMULIA User Assistance/Analysis Procedure; Dassault Systèmes: Vélizy-Villacoublay, France, 2019.

29. Belytschko, T.; Black, T. Elastic crack growth in finite elements with minimal remeshing. Int. J. Numer. Methods Eng. 1999, 45, 601-620. [CrossRef]

30. Barbero, E. Finite Element Analysis of Composite Materials Using Abaqus ${ }^{\mathrm{TM}}$; CRC Press: Boca Raton, FL, USA, 2013; p. 444.

31. Barbero, E. Introduction to Composite Materials Design, 3rd ed.; CRC Press: Boca Raton, FL, USA, 2017 ; p. 534.

32. Aboudi, J.; Arnold, S.M.; Bednarcyk, B.A. Micromechanics of Composite Materials: A Generalized Multiscale Analysis Approach, 1st ed.; Butterworth-Heinemann Ltd.: Oxford, UK, 2013.

33. European Committee for Standardization. Wood-Based Panels_Determination of Moisture Content; EN 322; European Committee for Standardization: Brussels, Belgium, 1993.

34. European Committee for Standardization. Wood-Based Panels-Determination of Density; EN 323; European Committee for Standardization: Brussels, Belgium, 1993.

35. European Committee for Standardization. Wood-Based Panels-Determination of Dimensional Changes Associated with Changes in Relative Humidity; EN 318; European Committee for Standardization: Brussels, Belgium, 2002.

36. European Committee for Standardization. Particleboards and Fiberboards-Determination of Swelling in Thickness after Immersion in Water; EN 317; European Committee for Standardization: Brussels, Belgium, 1993.

37. European Committee for Standardization. Particleboards and Fibreboards—Determination of Tensile Strength Perpendicular to the Plane of the Board; EN 319; European Committee for Standardization: Brussels, Belgium, 1993.

38. European Committee for Standardization. Wood-Based Panels-Determination of Modulus of Elasticity in Bending and of Bending Strength; EN 310; European Committee for Standardization: Brussels, Belgium, 1993.

39. Ahmed, S.A.; Adamopoulos, S. Acoustic properties of modified wood under different humid conditions and their relevance for musical instruments. Appl. Acoust. 2018, 140, 92-99. [CrossRef]

40. Rowell, R.M.; Ibach, R.E.; McSweeny, J.; Nilsson, T. Understanding decay resistance, dimensional stability and strength changes in heat-treated and acetylated wood. Wood Mater. Sci. Eng. 2009, 4, 14-22. [CrossRef] 
41. Ayrilmis, N. Effect of panel density on dimensional stability of medium and high density fiberboards. J. Mater. Sci. 2007, 42, 8551-8557. [CrossRef]

42. Ganev, S. Modeling of the Hygromechanical Warping of Medium Density Fiberboard. Ph.D. Thesis, Forestry Faculty, University of Laval, Québec, QC, Canada, 2002.

43. Bekhta, P.; Niemz, P. Effect of relative humidity on some physical and mechanical properties of different types of fibreboard. Eur. J. Wood Wood Prod. 2009, 67, 339-342. [CrossRef]

44. Pritchard, J.; Ansell, M.P.; Thompson, R.J.H.; Bonfield, P.W. Effect of two relative humidity environments on the performance properties of MDF, OSB and chipboard. Wood Sci. Technol. 2001, 35, 395-403. [CrossRef]

45. McNatt, J.D.; Wellwood, R.W.; Bach, L. Relationships between small-specimen and large panel bending tests on structural wood-based panels. For. Prod. J. 1990, 40, 10-16.

46. Wu, Q.; Suchsland, O. Effect of moisture on the flexural properties of commercial oriented strandboards. Wood Fiber Sci. 1997, 29, 47-57.

47. Halligan, A.F.; Schniewind, P. Prediction of particleboard mechanical properties at various moisture contents. Wood Sci. Technol. 1974, 8, 68-78.

48. Feist, W.C.; Rowell, R.M.; Ellis, W.D. Moisture sorption and accelerated weathering of acetylated and methacrylated aspen. Wood Fiber Sci. 1991, 23, 128-136.

49. Kojima, Y.; Suzuki, S. Evaluating the durability of wood-based panels using internal bond strength results from accelerated aging treatments. J. Wood Sci. 2011, 57, 7-13. [CrossRef]

50. Nocetti, M.; Brancheriau, L.; Bacher, M.; Brunetti, M.; Crivellaro, A. Relationship between local and global modulus of elasticity in bending and its consequence on structural timber grading. Eur. J. Wood Wood Prod. 2013, 71, 297-308. [CrossRef]

51. Akitsu, H.; Norimoto, M.; Morooka, T.; Rowell, R.M. Effect of humidity on vibrational properties of chemically modified wood. Wood Fiber Sci. 1993, 25, 250-260.

52. Bos, F.; Casagrande, S. On-line non-destructive evaluation and control of wood-based panels by vibration analysis. J. Sound Vib. 2003, 268, 403-412. [CrossRef]

53. Guan, C.; Liu, J.; Zhang, H.; Wang, X.; Zhou, L. Evaluation of modulus of elasticity and modulus of rupture of full-size wood composite panels supported on two nodal-lines using a vibration technique. Constr. Build. Mater. 2019, 218, 64-72. [CrossRef]

54. Souza, F.V.; Castro, L.S.; Camara, S.L.; Allen, D.H. Finite-element modeling of damage evolution in heterogeneous viscoelastic composites with evolving cracks by using a two-way coupled multiscale model. Mech. Compos. Mater. 2011, 47, 95-108. [CrossRef]

55. Šliseris, J.; Andrä, H.; Kabel, M.; Dix, B.; Plinke, B.; Wirjadi, O.; Frolovs, G. Numerical prediction of the stiffness and strength of medium density fiberboards. Mech. Mater. 2014, 79, 73-84. [CrossRef]

56. Huč, S.; Hozjan, T.; Svensson, S. Rheological behavior of wood in stress relaxation under compression. Wood Sci. Technol. 2018, 52, 793-808. [CrossRef]

Publisher's Note: MDPI stays neutral with regard to jurisdictional claims in published maps and institutional affiliations.

(C) 2020 by the authors. Licensee MDPI, Basel, Switzerland. This article is an open access article distributed under the terms and conditions of the Creative Commons Attribution (CC BY) license (http://creativecommons.org/licenses/by/4.0/). 